\title{
Limited Scleroderma with Pauci-Immune Glomerulonephritis in the Presence of Renal Cell Carcinoma
}

\author{
Victor Abrich, MD; Sudhir Duvuru, MD; and Howard J. Swanson, MD
}

\begin{abstract}
Connective tissue disorders increase the risk of malignancy; conversely, they may manifest as rheumatological paraneoplastic syndromes due to an underlying malignancy. We describe the case of a patient with limited scleroderma whose rapid disease progression coincided with the discovery of a renal tumor. A woman, age 75 years, presented with a 3-month history of progressive difficulty grasping objects, unsteadiness, dyspnea, xerostomia, xerophthalmia, and significant weight loss. She had a 10-year history of gastroesophageal reflux and Raynaud's phenomenon. Pertinent physical examination findings included facial telangiectasias, bibasilar inspiratory rales, sclerodactyly, and absent pinprick and vibratory sensation in her toes. She also had swelling and tenderness in several metacarpophalangeal and interphalangeal joints and in both ankles. A renal mass was demonstrated on abdominal computed tomography. A left partial nephrectomy was performed, confirming an unclassified type of renal cell carcinoma, along with a focal proliferative crescentic pauci-immune glomerulonephritis. Medical therapy with rituximab, pulse methylprednisolone, and prednisone led to improvement in her symptoms. The patient's presentation is consistent with a rapid progression of pre-existing limited scleroderma with the development of new rheumatological symptoms, including vasculitis. We propose that this progression was secondary to paraneoplastic stimulation by the renal cell carcinoma. Clinicians should consider looking for a malignancy in patients with connective tissue disorders who present with a myriad of new symptoms.
\end{abstract}

Keywords: Connective Tissue Diseases; Complications; Renal Cell Carcinoma; Etiology; Neoplasms; Scleroderma; Pauci-immune crescentic glomerulonephritis

Corresponding Author:

Victor Abrich, MD

Marshfield Clinic

Department of Internal Medicine

1000 North Oak Avenue

Marshfield, WI 54449 USA

Tel: (7I5) 387-550I

Fax: (715) 389-5757

E-mail: abrich.victor@marshfieldclinic.org

Received: December 21, 2012

Revised: February 28, 2013

Accepted: March 6, 2013

doi: $10.3121 / \mathrm{cmr} .2013 .114 \mid$
$\mathrm{P}$ with connective tissue disorders are at increased risk of developing malignancies, predominantly lymphoproliferative diseases. ${ }^{1}$ The primary risk factor appears to be sustained inflammation. ${ }^{1}$ Scleroderma in particular has been most commonly associated with lung cancer, hematological malignancies, and non-melanoma skin cancers. ${ }^{2}$ Patients with scleroderma have an estimated overall 1.5 to 2.4 -fold increase in risk of developing a malignancy. ${ }^{3}$

Alternatively, connective tissue disorders may manifest as rheumatological paraneoplastic syndromes. Although the mechanism remains unclear, tumors may induce such disorders through the secretion of hormones, cytokines, peptides, and other mediators. ${ }^{4}$ These disorders may manifest at the time of malignancy diagnosis, or appear several years before or after the diagnosis. ${ }^{5}$ Rheumatic manifestations in scleroderma patients have improved with treatment for a co-existing malignancy, while relapse has led to symptom recurrence. ${ }^{5}$ 


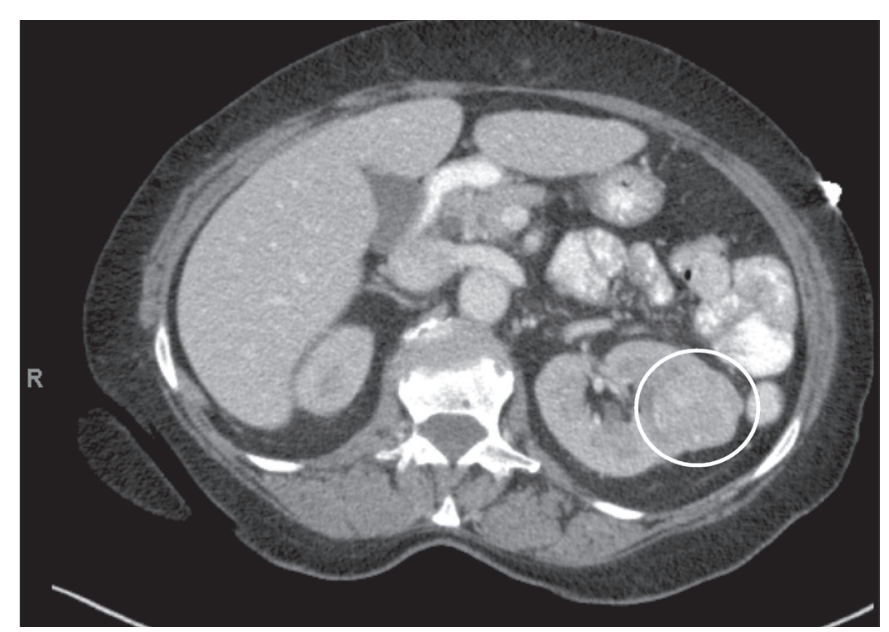

Figure 1. Abdominal computed tomography scan revealing a left renal mass (circled).

We describe a patient with limited scleroderma whose rapid disease progression coincided with the discovery of a renal tumor.

\section{Case Presentation}

A woman, age 75 years, presented with a 3-month history of difficulty grasping objects, unsteadiness on her feet, progressive shortness of breath, dryness of the eyes and mouth, and a 35-pound weight loss. She described a 10-year history of gastroesophageal reflux disease and Raynaud's phenomenon with progressive skin tightening in her hands. Additional medical history included exercise-induced asthma, degenerative joint disease, and depression. Her vital signs showed a temperature of $98.1^{\circ} \mathrm{F}$, blood pressure $119 / 72$ $\mathrm{mmHg}$, heart rate 82 beats/minute, and oxygen saturation $100 \%$ on 2 liters nasal cannula. Family history was positive only for her father, who had died of a myocardial infarction at age 61. The patient denied any smoking or alcohol use. Physical examination was significant for facial telangiectasias in a malar distribution, bibasilar inspiratory rales, sclerodactyly, and absent pinprick and vibratory sensation in her toes. Several metacarpophalangeal joints, proximal interphalangeal joints, and both of her ankles were swollen and tender, showing evidence of synovitis.

Laboratory tests showed the following abnormalities (normal values are shown in brackets): white blood cell count $24.1 \mathrm{x}$ $10^{3} / \mu \mathrm{L}\left[4.1-10.9 \times 10^{3} / \mu \mathrm{L}\right]$, platelets $730 \times 10^{9} / \mathrm{L}[150-450 \times$ $\left.10^{9} / \mathrm{L}\right]$, hemoglobin $11.1 \mathrm{~g} / \mathrm{dL}[12-16 \mathrm{~g} / \mathrm{dL}]$, erythrocyte sedimentation rate (ESR) $79 \mathrm{~mm} / \mathrm{hr}[0-20 \mathrm{~mm} / \mathrm{hr}]$, C-Reactive protein (CRP) $15.5 \mathrm{mg} / \mathrm{dL}$ [0-1.0 $\mathrm{mg} / \mathrm{dL}]$, a polyclonal increase in immunoglobulin $\mathrm{G}(\mathrm{IgG})$ of $1720 \mathrm{mg} / \mathrm{dL}$ [700$1600 \mathrm{mg} / \mathrm{dL}]$, antinuclear antibody-human epithelial cell line 2 (ANA-Hep2) titer of 1:160 [<1:40], rheumatoid factor 80 $\mathrm{IU} / \mathrm{mL}[<10 \mathrm{IU} / \mathrm{mL}]$, Sjögren's Syndrome Antibodies (SSA) $>8.0 \mathrm{U}[0-0.9 \mathrm{U}]$, absent anti-centromere antibodies, positive cytoplasmic anti-neutrophil cytoplasmic antibodies (c-ANCA), and proteinase 3 (PR3) antibodies $>8.0 \mathrm{U}$ [0-0.9 U]. Urinalysis revealed $3+$ hematuria, iron studies demonstrated anemia of chronic disease, and liver enzymes were elevated: aspartate amino transferase (AST) $48 \mathrm{IU} / \mathrm{mL}$ [ $<35 \mathrm{IU} / \mathrm{mL}$ ], alanine amino transferase (ALT) $63 \mathrm{IU} / \mathrm{mL}$ $[<35 \mathrm{IU} / \mathrm{mL}]$, and alkaline phosphatase $339 \mathrm{IU} / \mathrm{mL}[50-136$ $\mathrm{IU} / \mathrm{mL}]$. Nerve conduction studies and electromyography revealed a length-dependent, predominantly axonal, mixed sensorimotor neuropathy. Computed tomography of the chest and abdomen revealed a patulous esophagus, pulmonary fibrosis, and a left renal mass suggestive of a malignancy (figure 1).

A left partial nephrectomy was performed, demonstrating a renal cell carcinoma with features of oncocytoma and chromophobe renal cell carcinoma. The final diagnosis was renal cell carcinoma, unclassified. Microscopic examination of non-neoplastic renal parenchyma revealed focal segmental glomerulonephritis with fibrous crescents and interstitial inflammation, though no active vasculitis was present. These changes were deemed consistent with pauci-immune crescentic glomerulonephritis. Postoperatively, the patient's course was complicated by bilateral lower extremity deep venous thromboses, necessitating anticoagulation with warfarin.

Medical treatment was started one month before surgery. The patientreceived threepulses of intravenous methylprednisolone before being placed on modest doses of oral prednisone. She also received two doses of rituximab; the first was administered soon after the first pulse of methylprednisolone, and the second was administered after the surgery. After starting medical therapy, she experienced clinical improvement in her sclerodactyly, polyarthritis, and dyspnea. Her renal function also showed some improvement, and with medical therapy, her creatinine decreased from $1.2 \mathrm{mg} / \mathrm{dL}$ to $1.0 \mathrm{mg} / \mathrm{dL}$ and estimated glomerular filtration rate (eGFR) increased from 44 $\mathrm{mL} / \mathrm{min} / 1.73 \mathrm{~m}^{2}$ to $57 \mathrm{~mL} / \mathrm{min} / 1.73 \mathrm{~m}^{2}$, suggesting only a modest response to treatment. After the left partial nephrectomy, the creatinine further decreased to $0.9 \mathrm{mg} / \mathrm{dL}$ with the eGFR increasing to $61 \mathrm{~mL} / \mathrm{min} / 1.73 \mathrm{~m}^{2}$. The patient's liver enzymes normalized, CRP decreased to $0.4 \mathrm{mg} /$ $\mathrm{dL}$, white blood cell count decreased to $13.5 \times 10^{3} / \mu \mathrm{L}$, and the hemoglobin increased to $12.1 \mathrm{~g} / \mathrm{dL}$. Half a year later, the patient reported increased range of motion in her hands and marked improvement in the dryness of her eyes and mouth. She also reported better sensation in her fingers and toes, which was accompanied by a return of pinprick and vibration sensation on neurological exam. Her synovitis had resolved, and the urinalysis was devoid of hematuria.

\section{Discussion}

Our patient's disease prior to presentation is consistent with limited scleroderma, also known as CREST syndrome (calcinosis, Raynaud's phenomenon, esophageal dysmotility, sclerodactyly, telangiectasias). On presentation, she exhibited rapid disease progression with development of subacute pulmonary fibrosis, polyarthritis, a sensorimotor neuropathy, and a pauci-immune crescentic glomerulonephritis. Pulmonary fibrosis commonly occurs as a late complication 
in patients with limited scleroderma, and is associated with the development of pulmonary hypertension. ${ }^{7}$ In contrast, pauci-immune crescentic glomerulonephritis is rare in scleroderma. When it does occur, the anti-neutrophil cytoplasmic antibody specificity is usually directed against myeloperoxidase. ${ }^{8}$ The vasculitis typically affects the small vessels, and can be observed in up to one third of tissue biopsies. ${ }^{9}$ Malignancy has been suggested as a trigger for the development of ANCA-positive vasculitis, which has been seen in association with urinary tract cancers. ${ }^{10}$

Our patient developed a sensorimotor neuropathy, which is commonly associated with scleroderma. Damage to the peripheral nerves typically involves a combination of axonal demyelination and lesions affecting the nerve fibers, causing a mixed neuropathy. ${ }^{11}$ Damage occurs as a result of ischemia secondary to vasculitis of the vasa nervorum, and also from humoral and cell-mediated autoimmune destruction. ${ }^{11}$ Renal cell carcinomas can also produce peripheral neuropathies through a paraneoplastic mechanism. However, this is unlikely in our patient since peripheral neuropathies associated with renal cell carcinoma tend to impact either the sensory or motor nervous system. ${ }^{12}$

Based on the sequence of events, the patient likely suffered from limited scleroderma that went undiagnosed for several years. With the new finding of a renal tumor, the rapid development of new symptoms in our patient would suggest paraneoplastic stimulation by the renal cell carcinoma causing a progression of her disease. The latter is suggested by our patient's serology, since the presence of SSA antibodies may be a marker for malignancy in the context of certain autoimmune phenomena. ${ }^{13}$ This is further supported by the presence of elevated liver transaminases, a known paraneoplastic manifestation of renal cell carcinoma called Stauffer's syndrome. ${ }^{12}$ Despite these clues, it is important to consider that the patient's new symptoms could have also occurred as a natural progression of the limited scleroderma, with the renal tumor being an incidental finding. Unfortunately, we can only speculate regarding pathogenesis, since primary and paraneoplastic presentations of connective tissue disorders are indistinguishable. ${ }^{5}$

Although the initial discovery of our patient's connective tissue disorder and malignancy occurred in the inpatient setting, treatment was initiated as an outpatient. Unfortunately, the partial nephrectomy was scheduled one month after discharge. Due to the uncertainty of the disease process, the decision was made to begin medical therapy before surgery to prevent progression to end-stage renal failure in the setting of ANCA-positive disease. Treatment with steroids and rituximab occurred before and after surgery, with the patient's symptoms gradually improving. If her symptoms had been secondary to paraneoplastic stimulation, then immediate surgery would have been therapeutic, potentially reducing her immunosuppressive therapy requirement. However, positive response to surgery alone could not be observed due to concurrent medical therapy.
Clinicians should consider looking for a malignancy in patients with connective tissue disorders who present with a myriad of new symptoms. If detected, treatment should be initially guided towards eradication of the malignancy in the event that the symptoms are secondary to paraneoplastic stimulation. This may reduce the amount of additional immunosuppressive therapy required to treat the rheumatological disease.

\section{References}

1. Szekanecz Z, Szekanecz E, Bakó G, Shoenfeld Y. Malignancies in autoimmune rheumatic diseases - a mini-review. Gerontology 2011;57:3-10.

2. Rosenthal AK, McLaughlin JK, Gridley G, Nyren O. Incidence of cancer among patients with systemic sclerosis. Cancer 1995;76:910-914

3. Leandro MJ, Isenberg DA. Rheumatic diseases and malignancy-is there an association? Scand J Rheumatol 2001;30: $185-188$

4. Hall TC. Paraneoplastic syndromes: mechanisms. Semin Oncol 1997;24:269-276.

5. Ciołkiewicz M, Domysławska I, Ciołkiewicz A, Klimiuk PA, Kuryliszyn-Moskal A. Coexistence of systemic sclerosis, scleroderma-like syndromes and neoplastic diseases. Pol Arch Med Wewn 2008;118:119-126.

6. Balbir-Gurman A, Braun-Moscovici Y. Scleroderma overlap syndrome. Isr Med Assoc J 2011;13:14-20.

7. Sweiss NJ, Hushaw L, Thenappan T, Sawaqed R, Machado RF, Patel AR, Gomberg-Maitland M, Husain AN, Archer SL. Diagnosis and management of pulmonary hypertension in systemic sclerosis. Curr Rheumatol Rep 2010;12:8-18.

8. Chan PT, Mok CC. Pauci-immune crescentic glomerulonephritis in limited cutaneous systemic sclerosis. Clin Rheumatol 2012;31:1273-1277

9. Kambham N. Crescentic Glomerulonephritis: an update on Pauci-immune and Anti-GBM diseases. Adv Anat Pathol 2012;19:111-124.

10. Edgar JD, Rooney DP, McNamee P, McNeill TA. An association between ANCA positive renal disease and malignancy. Clin Nephrol 1993;40:22-25.

11. Spirin NN, Bulanova VA, Pizova NV, Shilkina NP. Peripheral nervous system lesion syndromes and the mechanisms of their formation in connective tissue diseases. Neurosci Behav Physiol 2007;37:1-6.

12. Palapattu GS, Kristo B, Rajfer J. Paraneoplastic syndromes in urologic malignancy: the many faces of renal cell carcinoma. Rev Urol 2002;4:163-170.

13. Böckle BC, Stanarevic G, Ratzinger G, Sepp NT. Analysis of $303 \mathrm{Ro} / \mathrm{SS}-\mathrm{A}$ antibody-positive patients: is this antibody a possible marker for malignancy? Br J Dermatol 2012;167:1067-1075.

\section{Author Affiliations}

Victor Abrich, $M D^{*}$; Sudhir Duvuru, $M D^{*}$; and Howard J. Swanson, MD

*Department of Internal Medicine, Marshfield Clinic; Marshfield, Wisconsin, USA

Inpatient Medicine, Aultman Hospital, Canton, Ohio, USA

* Department of Rheumatology, Marshfield Clinic; Marshfield, Wisconsin, USA 